\title{
INTERCULTURALIDAD EN EL AULA DE MÚSICA DE EDUCACIÓN PRIMARIA. UN ESTUDIO DE CASO DESDE UNA PERSPECTIVA POSTCOLONIAL
}

\author{
José Luis Aróstegui y Alejandro Wolfgang Espigares \\ Universidad de Granada \\ arostegu@ugr.es, alejandroespigares@gmail.com
}

\begin{abstract}
Este artículo refiere un estudio de caso realizado en un aula de música en un Centro Público de Educación Primaria. Nuestro foco de atención estuvo tanto en la maestra de música y su método de enseñanza como en el alumnado y en los aprendizajes explícitos e implícitos producidos, con el propósito de estudiar desde una perspectiva intercultural el proceso de enseñanza-aprendizaje dentro del aula. Tras la recogida de datos y su posterior estudio encontramos que el interés por la transmisión de los aspectos técnicos de la música mediante la motivación del alumnado que emplea la maestra acaban dejando en un segundo plano la autenticidad de la experiencia musical, a pesar del interés que también tiene por la musicalidad y la participación del alumnado.
\end{abstract}

Palabras clave. Educación musical; escolarización obligatoria; enseñanza-aprendizaje; interculturalidad; postcolonialismo.

This paper refers a case study carried out in a music classroom situated in a public elementary school. Our focus was both on the teacher's way of teaching and the pupils' explicit and implicit learnings outputted in order to study from an intercultural approach how this process of teaching and learning is produced in that classroom. After collecting data and thereafter study, we found that the teacher's emphasis on the musical language aspects throughout the motivation of students in the end relegates to the background the authenticity of the musical experience, despite her interest for musicality and students empowerment.

Keywords: Music education; mandatory schooling; teaching-learning; interculturality; postcolonialism.

La educación musical en edades tempranas suele estar dirigida al desarrollo de habilidades sociales, psicomotrices y creativas $\mathrm{y}$, a medida que van creciendo, se le va prestando mayor atención a aspectos conceptuales relacionados con el lenguaje musical y con la Historia de la Música. Gracias fundamentalmente a la teoría crítica del currículo sabemos que de las propuestas de enseñanza del profesorado centradas en contenidos el alumnado acaba aprendiendo otras cosas en parte diferentes, dependiendo de las circunstancias contextuales de cada escuela, de cada grupo, de cada estudiante y de cada docente.

En este artículo referimos un estudio de caso ${ }^{1}$ que se hizo con el propósito de saber qué enseñaba una maestra de música en un centro público de Educación Primaria y qué acabaron aprendiendo los niños y niñas del aula de $2^{\circ}$ de Primaria estudiados en esta investigación, todo ello realizado desde una perspectiva intercultural. Lo hacemos desde un planteamiento investigador crítico (KINCHELOE Y MC LAREN, 2005) reconstruccionista del significado de las acciones en el que el investigador lleva adelante su indagación con miras a la mejora de la realidad observada, posicionamiento del que fue precursor STENHOUSE (1998). Partimos igualmente de la posibilidad de transferir indirectamente a otros contextos los hallazgos de este estudio cualitativo mediante la generalización naturalista (STAKE, 2005).

Con estos fines en mente hemos estructurado el artículo en cuatro partes: 1) revisión de la literatura sobre interculturalidad que nos sirve como marco de interpretación de los datos; 2) exposición de los objetivos y diseño metodológico de nuestro estudio; 3) descripción e interpretación de los datos 
recogidos; 4) conclusiones a las que llegamos al estudiar nuestros datos desde el marco teórico expuesto inicialmente. Nuestro principal resultado es que encontramos a una maestra que desarrolla un enfoque técnico-práctico del currículo centrado en la enseñanza formal de la música y que relega a un segundo plano la diversidad cultural de sus estudiantes con la consiguiente pérdida de autenticidad de la experiencia musical, a pesar de su interés por fomentar la musicalidad y la participación de su alumnado.

\section{QUÉ ENTENDEMOS POR INTERCULTURALIDAD}

Cada persona entiende una misma situación de manera diferente dependiendo de las normas y conocimientos que rigen su cultura y que definen quién es en razón de su edad, clase social, género, etnia... entre otras muchas circunstancias socioculturales, lo que inevitablemente lleva a conflictos cuando a los mismos "hechos" se les da significados diferentes al percibirse desde perspectivas distintas. Con el fin de intentar comprender tales conflictos, se crean las categorías conceptuales de multiculturalidad e interculturalidad.

El multiculturalismo refiere la coexistencia de varias culturas dentro de una misma sociedad, conservando cada una su propia identidad sin modificación alguna a pesar de esa coexistencia simultánea, mientras que el interculturalismo alude a la interrelación entre culturas habiendo, por tanto, influencias mutuas entre ellas, conformando así unas fronteras difusas entre cada una. Es decir, el multiculturalismo es un modo de entender la diversidad, mientras que la interculturalidad estudia la misma existencia de esa diversidad (Arriarán y Hernández, 2010)².

El multiculturalismo estudia el contacto entre culturas, fundamentalmente en entornos urbanos y en ciertos países en donde los fenómenos migratorios y el acceso a las Tecnologías de la Información y la Comunicación han tenido un impacto en la mayoría de la población (ARÓSTEGUI E IBARRETXE, 2016). El multiculturalismo reconoce las asimetrías políticas y económicas y su impacto en la segregación, sobre todo racial, entendiéndose la heterogeneidad multicultural como yuxtaposición y dispersión entre grupos que aboga por garantizar los derechos individuales de las personas que pertenecen a una comunidad en concreto (GARCÍA CANCLINI, 1995), es decir, piensan y actúan como miembros de un grupo minoritario, como los afroamericanos en los Estados Unidos o la población gitana en Europa. Se esencializan así las identidades minoritarias y, por tanto, cada grupo cultural defiende sus diferencias lingüísticas, cuotas laborales o de reconocimiento de su diferencia en escuelas, universidades o instituciones públicas.

Por su parte, el interculturalismo entiende las relaciones entre culturas como un espacio social a compartir en donde las diferencias culturales conforman un todo que genera continuidad entre las mismas (Solís, 2001). Aquí el foco está en las convergencias culturales y en la búsqueda de similitudes, en lo que tienen en común entre ellas, prestando así atención al modo en que cada cultura interpreta y crea una "supracultura" con la que esa diversidad cultural se identifica. Esta supracultura puede jugar un papel importante a la hora de facilitar la coexistencia en situaciones sociales de confrontación entre grupos culturales y en la abolición de la xenofobia y la intolerancia de cualquier tipo (ibíd.).

Desde esta perspectiva, sólo una escuela intercultural es verdaderamente democrática, un lugar donde las diferencias se valoran y se basan en principios democráticos, pues la democracia implica el reconocimiento de las diferencias culturales entre grupos que, al mismo tiempo, forman parte de una sola comunidad (CASQUETTE, 2001). Por tanto, una escuela democrática debería favorecer la asimilación de las diferencias culturales (GIJón, 2005). En el momento en que negamos la diversidad cultural estamos creando una discriminación, ya que estamos tratando por igual lo que es diferente, con el resultado intencionado o no de que quien más próximo esté al modelo cultural homogéneo que ofrezca la escuela estará en mejores condiciones para tener éxito que quien esté más alejado. Necesitamos, pues, una educación intercultural entendida como la "búsqueda de valores y principios que pueden ser compartidos por todo el mundo" (PÉREZ TAPIAS, 2013, p. 152) 
si es que queremos educar sin imponer el modelo cultural de un grupo sobre otro y sin discriminar a quien menos se adapte a él.

\section{Educación musical e interculturalidad}

La música es una de las vías utilizadas en educación intercultural para mostrar la diversidad cultural (SCHIPPERS, 2010). El primer y más evidente cambio que se puede observar en el currículo y en su correspondiente formación del profesorado hacia una educación musical multi o intercultural ha sido la introducción de las llamadas "músicas y danzas del mundo" provenientes de diferentes culturas. De acuerdo con ANDERSON Y CAMPBELL (2010), los principales conceptos y cuestiones que hay que tener en cuenta para una educación musical multicultural son: 1) centrarse en los contenidos musicales que el profesorado tiene que enseñar y el alumnado aprender; 2) la "autenticidad" de las experiencias musicales que se ofrecen; 3) qué músicas debieran incluirse en el currículo escolar; 4) tener en cuenta los beneficios que la educación musical multicultural puede tener para el alumnado, los centros escolares y la sociedad.

El multiculturalismo en educación musical se desarrolló inicialmente desde una perspectiva etnomusicológica. Partiendo del pensamiento occidental de la Modernidad y la expansión colonial, la etnomusicología siempre mostró interés por lo "popular" y por "otras" culturas (CAMPBELL, 2013). Este interés por "los otros" se transfirió a la educación musical y a la formación del profesorado de música a partir de los años 60, con el fin de ampliar las percepciones musicales de los estudiantes y sus artífices (ibíd). Desde esta perspectiva, el alumnado debe conocer la diversidad musical considerada lo suficientemente valiosa como para enseñarse y aprenderse.

Pero, ¿qué entendemos por valioso en educación musical multi o intercultural y qué criterios hay que seguir para seleccionar las músicas apropiadas? La respuesta más común que dan diversos autores, Campbell entre ellos, es considerar la "autenticidad" de las manifestaciones musicales que se practican en el aula, entendiendo por "autenticidad" que la experiencia musical esté conectada con los entornos de donde surgen. Esto es una tarea muy difícil para la educación, ya que las escuelas están muy lejos de ser contextos "naturales" en comparación con los lugares donde dichas músicas se ejecutan regularmente. La solución a esta cuestión de la autenticidad nos la da GREEN (2006), para quien se le debe prestar más atención a la diversidad de los estudiantes y a sus necesidades que a la diversidad musical, vinculándose así la autenticidad de la experiencia musical con el significado que dichas experiencias tienen para los estudiantes. Es decir, la autenticidad pasa del producto musical al proceso de aprendizaje musical o, lo que es lo mismo, del constructo adulto sobre contenidos intelectuales a los aspectos culturales, estéticos, sociológicos y psicológicos de los estudiantes (PALMER, 1992). En otras palabras, tenemos que prestar atención a las necesidades y diversidad del alumnado antes que a los de la música (ARÓSTEGUI E IBARRETXE, 2016).

Una perspectiva multicultural que se centra en la diversidad de las culturas, intencionadamente o no, supone la división del mundo en dos: nuestra cultura y la de los demás. Esta dicotomía se usó ampliamente durante la Modernidad, en donde la cultura occidental consideró a ciertos grupos (v. g., hombres, blancos, propietarios, burgueses, adultos...) como civilizados, libres y por tanto superiores mientras que los demás (mujeres, quienes no son blancos, sin propiedades, proletarios, salvajes, y niños) como inferiores y, por tanto, desde esta lógica tenían que ser sometidos y protegidos (FERNÁNDEZ ENGUITA, 1999). Estas jerarquías basadas en oposiciones binarias explican cómo las diferencias se convierten en desigualdades, pues mientras nos centremos en el objeto cultural estamos considerando a todo el mundo igual, de ahí que, paradójicamente, una educación multicultural que parta de una dicotomía entre la música occidental y la de las "otras" culturas reproduzca las injusticias que está intentando contrarrestar.

En esta división del mundo en dos, libre y opresor uno, dominado y oprimido el otro, la música no es una excepción. Desde esta perspectiva, la música clásica occidental se consideraba por encima de las de los otros grupos culturales (p. ej., la compuesta por mujeres, la popular o étnica...), de ahí que no se tuvieran en cuenta en el ámbito académico. El multiculturalismo supuso en su momento 
un paso adelante en el reconocimiento de "otras" músicas (VOLK, 1998), pero en este momento de cambio hacia la Postmodernidad en el que nos encontramos es momento de una "educación musical mundial" (O'FLYNN, 2005) o intercultural que revise las asunciones implícitas sobre las posibilidades reales de un sistema universal de educación musical y que reconsidere la taxonomía de músicas "exóticas" subsumidas en una visión pan-occidental de la música y de la musicalidad y que, aun cuando se reconozcan, implican una asimilación cultural de las prácticas musicales occidentales presentadas como universales cuando, en realidad, se trata de un colonización cultural, una cuestión de mímesis (BHABHA, 1984; ASHCROFT, GRIFFTHS Y TIFFIN, 2013) de aquellas prácticas provenientes de la música clásica occidental que aún permanecen centrales.

\section{EL DISEÑO DE INVESTIGACIÓN}

Presentamos a continuación los datos provenientes de nuestra investigación realizada en un aula de música de $2^{\circ}$ de Educación Primaria con el fin de estudiar el proceso de enseñanza-aprendizaje desde una perspectiva intercultural. Nos interesa conocer qué es lo que la maestra de un centro público quiere enseñarle a sus estudiantes y qué es lo que estos acaban aprendiendo. De este modo nos preguntamos: ¿promueve la maestra un acercamiento entre las diversas culturas que se dan en el aula a través de la música o tal vez transmite el suyo?; ¿es propicio el ambiente musical que se crea en el aula para una educación intercultural o tal vez la cultura escolar impone un modelo dominante? Así, los objetivos de nuestra investigación son:

- Conocer cómo y hasta qué punto esta maestra fomenta la musicalidad, la creatividad y la identidad musical de sus estudiantes, y a partir de qué contenidos

- Conocer las estrategias que utiliza la maestra en el proceso de la enseñanza.

- Constatar cómo influye la música en los sentimientos y percepciones del alumnado.

Para llevar a cabo estos objetivos y preguntas de investigación, lo primero fue pedir acceso a un Centro Público de Educación Infantil y Primaria (CEIP). Tras contactar con la maestra de música, que encantada accedió a que pudiéramos asistir a sus clases, hablamos a continuación con el director del centro, quien no puso ningún obstáculo para que pudiésemos realizar el estudio, aunque nos pidió que solicitásemos autorización a la Delegación de Educación. Así lo hicimos y así conseguimos las correspondientes autorizaciones.

Este CEIP está situado en una población a las afueras de la ciudad de Granada. A pesar de su proximidad con la capital, el contexto de la escuela es más rural que urbano, al menos esa fue nuestra sensación en razón del trato más directo y cercano que percibimos entre alumnado y profesorado y la manera más extrovertida de comportarse chicos y chicas, entre otros motivos. Por otro lado, el alumnado del Centro era muy diverso, con estudiantes de diferentes procedencias, de ahí que pensáramos que fuera un contexto interesante para nuestros propósitos investigadores.

Estuvimos haciendo observación no participante durante seis semanas del tercer trimestre del curso 2014/2015 en los tres grupos de $2^{\circ}$ de Primaria del Centro, lo que hizo un total de 18 horas de observación. En cada aula había entre 20 y 25 alumnos, repartidos equitativamente entre niños y niñas. Tras el periodo de observación, concertamos una entrevista semiestructurada con la maestra, en donde le preguntamos sobre cómo motiva al alumnado, qué técnicas utiliza en el proceso de enseñanza-aprendizaje, cómo intenta resolver los problemas que surgen en las clases, entre otras cuestiones que se mencionan a continuación. 


\title{
DESCRIPCIÓN E INTERPRETACIÓN DE LOS DATOS
}

\section{La maestra}

La maestra, a la que llamaremos Ana, no posee estudios musicales formales, aunque sabe tocar la guitarra de forma autodidacta. A pesar de que durante las observaciones no la llevó a clase, los chicos y chicas se lo solían recordar. Su formación docente se basa en la carrera de magisterio como generalista. Debido a su interés por la música, realizó los cursos de capacitación pedagógica en los años 90 que la acreditaron como maestra especialista en educación musical, lo que le permitió ejercer desde entonces como profesora de música, una de sus grandes aficiones, pues ella misma confiesa que la asignatura de Música es la que más le gusta impartir.

Para la maestra es muy importante que los alumnos sepan reconocer las notas musicales y situarlas en el pentagrama, por eso las clases se centran en la enseñanza del lenguaje musical. Ella misma indica que "los niños cuando se van al instituto no saben apenas música, y mi objetivo es que al menos salgan sabiendo leer una partitura”. El siguiente fragmento es un buen ejemplo de ese interés por la lectoescritura musical de esta maestra en clase:

\begin{abstract}
Ana les ha entregado un folio plastificado con el pentagrama, al igual que cuatro fichas redondas a cada uno que representan sonidos. Luego ha explicado las líneas y los espacios. A continuación fue tocando con la flauta los sonidos mi y sol y los alumnos debían ir colocando las fichas en la línea correspondiente. La mayoría lo han hecho sin problemas, menos algunos que no estaban atentos. Tras varias repeticiones, le da una ficha en donde los chicos y chicas colocaban el sonido donde correspondiese. Por ejemplo, ponía L2, E3 (línea 2, espacio 3), etc., y tenían que ir colocando una redonda. Los alumnos conocen a estas alturas la nota mi y sol, y se han mostrado muy interesados en conocer la nota si. A la hora de cantar, entonaron muy, muy bien.
\end{abstract}

Aunque los niños comienzan las clases siempre muy atentos y participativos, con estas actividades conceptuales poco a poco van perdiendo la atención, lo que provoca que haya cada vez menos chicas y chicos haciéndole caso a la maestra a medida que avanza la clase. Esta pérdida gradual del interés por actividades relacionadas con el lenguaje musical no ocurre cuando se realizan otras prácticas como danzas, cantos, percusión corporal, audiciones musicales (de las que durante el periodo de observación ninguna fue de música culta occidental), etc.

Cuando realizan estas actividades prácticas no tienen ningún miedo a expresarse libremente en grupo. En cambio, cuando se les pide lo mismo en grupos pequeños o individualmente delante de la clase, la situación les produce cierto miedo y vergüenza, lo que les limita en sus movimientos y en su participación en la actividad:

\begin{abstract}
Para finalizar la clase, la maestra propuso que, con la misma música, fueran ellos los que decidieran los pasos. Al principio, casi la mitad de la clase sale voluntaria pero, a la hora de la verdad, todos se muestran muy tímidos, con vergüenza, inseguros y faltos de creatividad. Sólo hay dos chicas (ambas apuntadas a baile como actividad extraescolar) y un chico (que apenas sabe hablar español), que se muestran seguros y decididos a la hora de realizar sus pasos. Otros, en cambio, ni siquiera se mueven, mostrando una sonrisa de vergüenza, o lo hacen con movimientos poco claros y sin ideas. Otros se limitan a imitar alguno de los movimientos de la maestra.
\end{abstract}

Se hayan hecho actividades teóricas o prácticas, lo habitual cuando quedan pocos minutos para finalizar la clase es que los estudiantes no respondan a lo que la maestra les pide, momento en el que Ana les pone a colorear los dibujos que aparecen en las fichas de clase. Los niños se calman coloreando, de lo que se vale la maestra para el control del comportamiento del grupo. Cuando utiliza esta estrategia en mitad de una clase, consigue dicho control, pero luego resulta muy complicado volver otra vez al ambiente musical previo, ya que los niños se empeñan en acabar de colorear y, aunque la maestra pide que guarden bajo la mesa los colores y la ficha, algunos hacen caso omiso y siguen coloreando. Cuando quedan pocos minutos para finalizar la clase y la profesora nota que ya están cansados o, a veces, cuando se ha quedado sin ideas o material para finalizarla, también se vale del dibujo. Dibujar y colorear es claramente una estrategia de control de Ana tanto del comportamiento de sus estudiantes como del tiempo de clase. 
La maestra participa en dos coros en su tiempo libre, por lo que está claro que le gusta la música coral. Probablemente por este motivo la entonación es una parte fundamental de sus clases; la excelente entonación que tiene el grupo es consecuencia de un duro trabajo que no tiene resultado de buenas a primeras. Tal vez la principal dificultad para enseñarles a cantar sean los problemas que encuentran los alumnos a la hora de cantar a la misma altura que un instrumento. Cuando la maestra utiliza la flauta dulce, los niños no consiguen encontrar la nota que suenan en la flauta. En cambio, cuando la profesora canta esa nota, no suele haber problema en conseguir que entonen, además de manera muy notable, como ya hemos mencionado, si bien existen problemas a la hora de cantar con precisión en gran grupo. La maestra intenta que vayan todos a la vez llevando ella el pulso y, aunque a veces es efectivo, otras provoca que los niños vayan a contratiempo:

\begin{abstract}
La profesora les enseña, sólo con texto, una canción: "A la luna yo quiero subir, a bordo de una estrella. Hasta allí yo quiero ir". Los alumnos memorizan el texto rápidamente. Posteriormente, mediante la repetición, la profesora les enseña la melodía, con graves problemas de afinación en gran grupo. Una vez que los alumnos la saben bien, realizan una secuencia rítmica que habían aprendido al comenzar la clase bajo un patrón a tres partes (a-a-a) mientras cantan, pero ahora no consiguen realizarla bien porque ellos siguen un ritmo a cuatro $(a-a-a-a)$ en un compás de 4/4, y al hacer cuatro patrones de percusión en vez de tres, les crea problemas para cantar correctamente la melodía. Tras varios intentos y de explicarlo otra vez más detenidamente, la maestra no consigue que salga bien. Además, algunos alumnos empiezan a despistarse y hablar entre ellos. La profesora deja la actividad.
\end{abstract}

Para introducir la entonación, primero presenta únicamente el aspecto rítmico de la frase, utilizando alguna vocal. Después añade, junto al ritmo, el texto y, poco a poco, la parte melódica. Además, siempre que realiza alguna práctica de ritmo, acaba añadiéndole un texto (según nos dice, el primero que se le ocurre en el mismo momento, ya que la improvisación forma parte de su enseñanza) $\mathrm{y}$, en muchas ocasiones, acaba añadiendo melodías únicamente con intervalos de segundas y terceras. Estas melodías surgen a partir de canciones populares conocidas o simplemente piezas que ella conoce y le gustan.

La estrategia de repetición a la hora de enseñar es la más utilizada en las clases observadas, lo que funciona bien en ciertas actividades como las de entonación o ritmo, y no tanto cuando se les pide que realicen movimientos libres, pues una vez han visto los movimientos de la maestra, chicos y chicas no saben qué hacer y acaban realizando los mismos o se quedan quietos sin saber reaccionar. Aunque al principio se muestran muy convencidos y con ganas de realizar la actividad, lo cierto es que el alumnado no logra expresarse libremente, dado que tienden a imitar los movimientos de la maestra.

Ana suele ir a las clases con materiales fabricados por ella. Cabe destacar una escalera, donde cada escalón simula un tono o semitono, con una altura más pequeña. Cada escalón corresponde a una nota, que está ligada a un color, con lo que niños y niñas identifican la nota con el color. Así, cuando en una ficha la maestra pide que coloreen las notas que aparecen en el pentagrama, dependiendo de la nota, los niños la colorean de acuerdo a esta asociación previa de colores y notas que ha sido memorizada por casi todos los chicos y chicas. Las fichas que entrega, en su mayoría, son realizadas por ella a partir de ejercicios y recursos ya existentes que le parecen interesantes y también aporta otros creados por ella.

Ana no utiliza en el aula el libro de Música que provee una editorial al CEIP debido a que no le parece interesante lo que propone, ya que "siempre son las mismas actividades pero de diferente forma, y los dibujos crean confusión en los alumnos porque no tienen sentido con lo que intenta explicar". A pesar de ello, sí que se vale del libro de texto como guía para impartir sus clases, partiendo de la programación didáctica que aparece. El alumnado, a final de curso, crea su propio libro de música; la maestra les entrega una portada que cada uno decora a su gusto (dibujando instrumentos, símbolos musicales, etc.). Luego, se grapa esa portada junto con todas las fichas que han realizado durante el curso.

La evaluación de la asignatura se centra en la realización de estas fichas, consistente cada una en una serie ejercicios con los contenidos que han trabajado en clase. Para Ana, con estas fichas los 
niños y niñas demuestran si han atendido o no. Cada trimestre suele contar con cuatro o cinco fichas. A cada estudiante se la acaba poniendo una nota dependiendo de cómo ha trabajado dichas fichas y de cómo ha sido su comportamiento y participación.

Música comparte nota con Plástica, pues en Primaria ambas forman parte de la asignatura de Educación Artística. En el Centro, ambos profesores se han puesto de acuerdo y, en el primer trimestre, se puso la nota de Música, en el segundo, la de Plástica y, para el tercer trimestre, se hace una media entre las dos asignaturas. A nuestro entender, con este modo de proceder se pierde el sentido de la evaluación continua y llega a crear confusión en alguna ocasión en los estudiantes, pues según nos dice la maestra se han dado casos donde un alumno es muy brillante en una de las dos materias mientras que no muestra interés en la otra, lo que conlleva un gran problema para ambos maestros a la hora de poner una calificación.

\section{El grupo clase}

Centrándonos ahora en el alumnado, dentro de las aulas encontramos mucha diversidad de niños. Por un lado, habría grupos homogéneos de españoles payos, españoles gitanos, y marroquíes. Mencionar su procedencia étnica nos parece importante para comprender la diversidad cultural en esta aula, pues encontramos diferentes pautas de comportamiento y de actitud hacia la música que parecen corresponderse a diferencias culturales en razón de su procedencia étnica.

En una de las clases hay un alumno, al que llamaremos Hassim, de origen marroquí. Apenas conoce el castellano, tiene cierta idea, pero no siempre sabe cómo expresarse y hay muchas palabras que no entiende. La profesora se dirige a él hablándole de forma más lenta y, si el alumno no responde, se ayuda de gesticulaciones en la repetición de las palabras. La maestra también le insta muy a menudo a que vaya repitiendo lo que ella le ha dicho, sobre todo con palabras más complejas. De la misma manera, cuando aparecen palabras nuevas dentro de la clase de Música, hace que las vaya repitiendo. Sus compañeros siempre intentan ayudarle. A pesar de ello, le resulta bastante complicado realizar correctamente la repetición de las palabras aunque, cuando consigue memorizar alguna, suele utilizarla reiteradamente para que la maestra vea que la ha aprendido.

En otra de las clases hay una alumna, a la que llamaremos Rosalía, de la que la profesora nos explica que no sabe expresarse y conoce muy poco vocabulario. Rosalía fue adoptada hace unos años, usa como nombre y apellidos el de la madre y el padre adoptivos, para que los biológicos no vengan a por ella desde su ciudad natal, ya que, según nos dijo la maestra, estos ya han intentado ponerse en contacto con la niña. Por sus rasgos faciales también parece ser magrebí.

Aunque no conocimos en profundidad su historia, sabemos que esta chica nació con una deficiencia auditiva severa. Cuando los médicos se percataron le pusieron un audífono, pero esto sucedió tarde y, por eso, su desarrollo lingüístico va muy por detrás en comparación con el nivel del resto de sus compañeros. Las causas de su retraso pueden ser fisiológicas, pero que no se detectaran precozmente son sociales, con lo que su desventaja física inicial se vio agrandada. Aunque intenta expresarse, lo hace con balbuceos y sin palabras claras. La maestra utiliza la misma técnica que con Hassim, en un intento de que Rosalía consiga entender y aprender algo más de lo que lo hace, aunque esta chica no reacciona de la misma forma que él, ya que le cuesta mucho más trabajo. La maestra no tiene muy claro qué hacer para ayudarla. Su carácter infantil, más que el del resto de sus compañeros, hace que pierda la concentración constantemente en clase y busque jugar con cualquier objeto que tenga al alcance de la mano.

Otra chica a destacar es Noelia, que se incorporó al Centro con el curso ya empezado, concretamente llegó en mitad del periodo de observación. Esta es una situación frecuente en el Centro, según nos cuenta la maestra, ya que suele haber estudiantes que se incorporan al colegio en mitad del curso o que se marchan. En su caso, se mostró algo tímida en la primera clase, pero en la siguiente ya era una más del grupo. La profesora lo vio como muy buena noticia no sólo para 
Noelia y el grupo, también para ella, pues, según nos dice, "la mayoría de los alumnos que suelen llegar en mitad de curso suelen ser problemáticos". No entendíamos qué relación hay entre incorporarse al Centro y "ser problemáticos", a lo que Ana nos explicó que, en muchas ocasiones, la entrada de un nuevo alumno en mitad del curso hace que el ambiente en las clases sea diferente al que todos ya estaban acostumbrados, de ahí que ni a ella ni a la mayoría de los maestros les gusten estas incorporaciones con el curso empezado. Como vemos, que un chico o chica pueda "ser problemático" no tiene necesariamente que ver con el nuevo estudiante, sino con el hecho de que la maestra vea truncada su dinámica de clase debido a esta incorporación.

La mayoría de los niños de este grupo ya tienen perfilada su identidad musical, tal como pudimos comprobar cuando algunos incluso se ofrecieron a cantar delante de todo el mundo aquellos géneros musicales de su interés. Así, un niño de etnia gitana cantó un fandango, mientras que otro payo realizó un rap. A partir de estas actuaciones, otros pidieron salir a cantar. Parece ser que, una vez que ven a sus compañeros actuar, los alumnos y alumnas pierden ese miedo escénico del que hablábamos antes:

\begin{abstract}
Al finalizar la clase, dos chicos se han acercado a la maestra para ver si podían cantar. La profesora les ha dicho que sí y han cantado, muy vergonzosos, una pieza flamenca. Tras ellos, otros dos chicos han querido salir a rapear, y luego un chico y una chica para cantar una canción pop. Durante las interpretaciones, algunos seguían trabajando en las fichas, otros se ponían a bailar y otros incluso cantaban desde sus pupitres acompañando a sus compañeros. Mientras iban actuando, observo rostros de felicidad.
\end{abstract}

\title{
CONCLUSIONES
}

A partir de los datos expuestos se observa que la enseñanza de esta maestra se centra en la enseñanza formal de la música, concretamente en el lenguaje musical y también en el canto, lo que se corresponde con los intereses musicales de la maestra (el canto) y con su concepto de lo que debe ser la educación musical escolar (que lleguen al instituto sabiendo leer una partitura). Así, en sus clases, los alumnos aprenden una serie de contenidos relacionados con los parámetros musicales mediante estrategias motivadoras que se van repitiendo con el objetivo de adquirir una serie de habilidades que sirve para sus propósitos técnicos y que en pocos casos ayuda al desarrollo de la musicalidad. Las experiencias musicales quedan así despojadas de su autenticidad, al menos de aquella que proviene del aprendizaje musical producido por los propios estudiantes a partir de sus propios contextos culturales. Donde mejor se evidencia esta falta de autenticidad de las prácticas artísticas es en las actividades de dibujo que realiza la maestra, donde lejos de potenciarse la parte artística o una interrelación entre música y plástica se emplea como estrategia de control del comportamiento y del tiempo de clase. Lo mismo cabe decir de la evaluación en el que la configuración del currículo, con una asignatura de Educación Artística compuesta por Música y Plástica acaba por distorsionar el concepto de evaluación continua.

El repertorio escolar empleado, consistente en piezas musicales pensadas para el aprendizaje de algún elemento del lenguaje musical de una manera atrayente para los niños y niñas, tampoco ayuda al fomento y reconocimiento de la diversidad cultural presente en el aula, en donde se mantiene el referente de la música culta occidental, aunque curiosamente no se trabaje directamente en el aula. Esta afirmación aparentemente contradictoria (si no aparece la música clásica, ¿por qué decimos que se mantiene como referente?) no lo es si tenemos en cuenta el contexto histórico en el que surgen y los propósitos de las metodologías musicales activas de los que esta maestra parte, que están en consonancia con los intereses musicales y en realidad vitales de la maestra. A fin de cuentas, "enseñamos quiénes somos" (WEISS, 2014: 190) lo que, por un lado, es nuestra única opción coherente con nuestra propia identidad docente, sonora y, en definitiva, social, pero que, siguiendo a este autor, deberíamos seguir sin pervertir la de los propios estudiantes y sin imponer nuestra visión del mundo o, más concretamente en nuestro caso, de la música. Ese "enseñar quién es Ana" funciona para los propósitos educativos y musicales que persigue esta maestra no sólo por los aprendizajes conseguidos, también porque la clase de Música es una de las que más gustan en la 
escuela al tener mayor libertad que en otras asignaturas y porque disfrutan realizando las actividades que propone la maestra.

Al mismo tiempo, desde una perspectiva intercultural se está reproduciendo un modelo cultural hegemónico adaptado al contexto escolar, perdiéndose así una oportunidad de visibilizar las diferencias culturales que en este caso vienen dadas fundamentalmente por la procedencia étnica del alumnado. El caso descrito en el que un niño pide cantar un fandango en clase y luego otros dos piden cantar un rap y a continuación otra niña una canción pop es uno de esos momentos excepcionales en el que se visibiliza esa diversidad que surge por iniciativa de los propios chicos y chicas y que la maestra acepta de buen grado, pero que en líneas generales se desaprovecha en los grupos observados, a pesar de la rica diversidad cultural existente.

Como ya hemos mencionado, la educación pública es necesariamente intercultural (PÉREZ TAPIAS, 2013), de modo que en el aula de música debería haber espacio para música infantil, clásica, flamenco, rap, pop, o cualquier otro estilo que sea auténtico y relevante para la identidad del alumnado. La maestra de este Centro, aun recogiendo las iniciativas del alumnado, mantiene los contenidos conceptuales de un modelo cultural en concreto que parece responder a una asimilación y mímesis cultural (BHABHA, 1984; ASHCROFT, GRIFFITHS Y TIFFIN, 2013) de las prácticas musicales de la música culta occidental; puede que el repertorio que se emplee sea otro, de carácter más escolar y que en muchos casos no tiene uso fuera de este contexto, pero el interés por lo técnico es el mismo que el de este estilo musical. Con esto no pretendemos decir que la música clásica no tenga lugar dentro de la escuela, nada más lejos de nuestras intenciones, tampoco que la escuela deba ser sólo un lugar de reproducción de las culturas de los estudiantes, sino que los criterios para desarrollar las prácticas de enseñanza provienen de un modelo cultural hegemónico en el que lo técnico antecede a la musicalidad, a costa de perder reconocimiento de las "otras" músicas presentes en el aula. Y esto a pesar del esfuerzo integrador de esta maestra, que se evidencia en la ayuda que la maestra ofrece a los alumnos que sufren dificultades idiomáticas, también permitiendo a los chicos expresar sus gustos musicales en clase -ya perfilados a sus siete años de edad-, como asimismo en el clima generado en clase, donde los niños se ayudan entre sí y aceptan con inmediatez a los recién llegados.

La escuela, más aún la intercultural, debe partir de los contextos culturales de los estudiantes y expandirlos, sólo así se conseguirá romper estereotipos y dicotomías. En esta ampliación, la música infantil, la música clásica y otras muchas tienen un papel muy importante, pero nunca más preeminente en este mundo global y líquido en el que vivimos. Para ello, la cultura escolar hegemónica debe dejar de serlo para fusionarse con las culturas del alumnado y crear, entre todos, una supracultura en la que cada uno aprende lo que le ofrece la escuela sin dejar de ser quienes son.

\section{Referencias}

Anderson, W. M. y CAMPBELl, P. S. (2010) Teaching music from a multicultural perspective. En W. M. Anderson y P. S. Campbell (ed.), Multicultural perspectives in music education. Lanham: MENC/Rowman y Littlefield Education.

ARÓSTEGUi, J. L. E IBARRETXE, G. (2016). Intercultural education and music teacher education: Cosmopolitan learning through popular music. En P. Burnard, E. Mackinlay and K. Powell (Ed.). The Routledge International Handbook of Intercultural Arts Research. Oxon-Nueva York: Routledge.

ARriARÁn, S. Y HERNÁNDEZ, E. (2010) El paradigma del multiculturalismo frente a la crisis de la educación intercultural, Cuicuilco 48, 87-105. Disponible en http://www.scielo.org.mx/scielo.php?pid=S0185-16592010000100006\&script=sci_arttext\&tlng=en

Ashcroft, B., Griffiths, G. Y Tiffin, H. (2013). Postcolonial studies. The key concepts. Nueva York: Routledge. 
BнавнA, H. (1984). Of mimicry and man: The ambivalence of colonial discourse, Discipleship: A Special Issue on Psychoanalysis. 28, 125-133.

CAmpbell, P. S. (2013). Etnomusicología y Educación Musical: Punto de encuentro entre música, educación y cultura. Revista Internacional de Educación Musical, 1, 42-52. doi: 10.12967/RIEM2013-1-p042-052

CASQuetTe, J. (2001) Vivencia y convivencia. Teoría social para una era de la información, Madrid: Trotta.

FERNÁNDEZ ENGUITA, M. (1999) La escuela a examen: un análisis sociológico para educadores y otras personas interesadas, Madrid: Pirámide.

García Canclini, J. (1995) Consumidores y Ciudadanos, Méjico: Grijalbo.

GiJón, J. (2005) La estrategia del "Ratón de Troya". Una propuesta para el trabajo colaborativo entre profesores en ambientes multiculturales. Profesorado, 9(1). Disponible en https://www.ugr.es/ recfpro/rev91COL4.pdf

GREEN, L. (2006) Popular music education in and for itself, and for 'other' music: Current research in the classroom, International Journal of Music Education, 24(2), 101-118.

KINCHELOE, J. L. Y MCLAREN, P. (2005). Rethinking critical theory and qualitative research. En N. K. Denzin e Y. S. Lincoln (Ed.). The Sage Handbook of Qualitative Research. Thousand Oaks: Sage.

MCLAREN, P. (1995) Critical pedagogy and predatory culture: Oppositional politics in a postmodern era. Londres y Nueva York: Routledge.

O'FlynN, J. (2005) Re-appraising ideas of musicality in intercultural contexts of music education, International Journal of Music Education, 23(3), 191-203.

PALMER, A. J. (1992) World musics in music education: The matter of authenticity, International Journal of Music Education, 19, 32-40.

PÉREZ TAPIAS, J. A. (2013). Educar desde la interculturalidad. Exigencias curriculares para el diálogo entre culturas. En J. Gimeno (ed.), Saberes e incertidumbres sobre el currículum. Madrid: Morata.

SCHIPPERS, H. (2010). Facing the music. Shaping music education from a global perspective. Nueva York: Oxford University Press.

Solís, D. (2001) Educación y diversidad cultural: breve agenda de investigación en educaciónpara la multiculturalidad. Ponencia presentada en la "Segunda Reunión Nacional de la Red de Educación Intercultural”, Universidad Pedagógica Nacional. Tepic, Nayarit, Méjico. Del 11 al 14 de noviembre. Disponible en http://www.socolpe.org/data/normalarmenia/BIBLIOGRAFIA/Educaci\%F3n\%20y\%20diversidad\% 20cultural.doc

STAKE, R. E. (2005). Investigación con estudios de caso. Madrid: Morata.

STENHOUSE, L. (1998). La investigación como base de la enseñanza. Madrid: Morata.

VolK, T. M. (1998) Music, education and multiculturalism. Foundations and principles, Nueva York: Oxford University Press.

WEISS, D. (2015). We teach who we are. Reflections on teaching for social justice with young children. En K. Winograd (ed.), Critical literacies and young learners: Connecting classroom practice to the common core. Nueva York y Londres: Routledge. 
Manuscrito recibido el 4/11/2015 y evaluado anónimamente. Aceptado para su publicación el 4/12/2016.

\footnotetext{
${ }^{1}$ Este estudio de caso es parte del proyecto de I+D EDU2014-58066-P del Ministerio de Economía y Competitividad sobre El Impacto de la Educación Musical en la Sociedad y en la Economía del Conocmiento.

${ }^{2}$ Los conceptos de multiculturalismo e interculturalismo no se emplean siempre de la misma manera, diferentes autores los emplean de distinto modo. Así, por ejemplo, Solís (2001), entre otros autores, los consideran equivalentes, mientras que MCLAREN (1995) define la interculturalidad como el lugar común compartido por las diferentes culturas. En este artículo seguimos la diferenciación entre estos conceptos de ARRIARÁN Y HERNÁNDEZ (2010).
} 